Research Article

\title{
A Model Study of Building Seismic Damage Information Extraction and Analysis on Ground-Based LiDAR Data
}

\author{
Fan Yang $\left(\mathbb{D},{ }^{1,2}\right.$ Xintao Wen, ${ }^{3}$ Xiaoshan Wang, ${ }^{2}$ Xiaoli Li, ${ }^{3}$ and Zhiqiang Li $\mathbb{D}^{3}$ \\ ${ }^{1}$ Institute of Geology, China Earthquake Administration, Beijing 100029, China \\ ${ }^{2}$ Hebei Earthquake Agency, Shijiazhuang 050021, China \\ ${ }^{3}$ China Earthquake Networks Center, Beijing 100045, China \\ Correspondence should be addressed to Zhiqiang Li; lzhq9028@163.com
}

Received 2 March 2021; Revised 23 March 2021; Accepted 27 March 2021; Published 8 April 2021

Academic Editor: Xueping Fan

Copyright (C) 2021 Fan Yang et al. This is an open access article distributed under the Creative Commons Attribution License, which permits unrestricted use, distribution, and reproduction in any medium, provided the original work is properly cited.

Earthquake disasters can have a serious impact on people's lives and property, with damage to buildings being one of the main causes of death and injury. A rapid assessment of the extent of building damage is essential for emergency response management, rescue operations, and reconstruction. Terrestrial laser scanning technology can obtain high precision light detection and ranging (LiDAR) point cloud data of the target. The technology is widely used in various fields; however, the quantitative analysis of building seismic information is the focus and difficulty of ground-based LiDAR data analysis processing. This paper takes full advantage of the high-precision characteristics of ground-based LiDAR data. A triangular network vector model (TIN-shaped model) was created in conjunction with the alpha shapes algorithm, solving the problem of small, nonvisually identifiable postearthquake building damage feature extraction bias. The model measures the length, width, and depth of building cracks, extracts the amount of wall tilt deformation, and labels the deformation zone. The creation of this model can provide scientific basis and technical support for postearthquake emergency relief, assessment of damage to buildings, extraction of deformation characteristics of other structures (bridges, tunnels, dams, etc.), and seismic reinforcement of buildings. The research data in this paper were collected by the author's research team in the first time after the 2013 Lushan earthquake and is one of the few sets of foundation of LiDAR data covering the full range of postearthquake building types in the region, with the data information mainly including different damage levels of different structural types of buildings. The modeling analysis of this data provides a scientific basis for establishing the earthquake damage matrix of buildings in the region.

\section{Introduction}

Earthquake disasters can have a serious impact on people's lives and property, with damage to buildings being one of the main causes of death and injury. Rapid assessment of damage to buildings after an earthquake is essential for emergency response, rescue operations, and postdisaster reconstruction [1]. China accounts for $7 \%$ of the world's land area and is responsible for about $33 \%$ of the world's continental earthquakes, resulting in more than $50 \%$ of the global earthquake death toll [2-7]. After a devastating earthquake, the seismic rating of a building's structural type plays a critical role in casualties. The extraction and analysis of seismic damage information of different types of structures can provide scientific basis and technical support for emergency rescue, damage assessment of buildings, extraction of deformation characteristics of other structures (bridges, tunnels, dams, etc.), and seismic reinforcement of buildings after an earthquake [8-10].

With the development of science and technology, the terrestrial laser scanning (TLS) as an emerging technology, gradually applied to various fields of measurement, highprecision light detection and ranging (LiDAR) point cloud data of target objects can be acquired [10]. TLS is a new sensing technology that uses laser reflection signals to measure the distance between the target and the scanner by emitting and receiving a laser beam and calculates the threedimensional coordinates of all sampled points on the target 
surface from the attitude angle of the scanner when the laser beam is emitted. Compared with traditional remote sensing technology, three-dimensional laser scanning technology has the ability to obtain accurate, fast, and real-time data on the true shape of the surface of the target object because it is based on the active measurement method, does not rely on visible light, has a more flexible operation mode $[11,12]$.

In recent years, terrestrial laser scanning technology has been widely used in different fields such as three-dimensional modeling, heritage protection, deformation monitoring, and forest structure investigation [13]. Experiments using TLS for continuous monitoring and analysis of building structural component damage demonstrate its effectiveness in structural modeling and analysis applications $[14,15]$; scanning assessment and 3D modeling of ancient buildings using TLS propose effective solutions for the conservation and maintenance of ancient buildings [16]; in civil engineering applications, high precision data obtained by TLS in combination with least squares are used for the quality assessment of building plane regularity [17]; scholars applied "alpha shapes algorithm" to LiDAR data contour line extraction and regularization for buildings and demonstrated the accuracy of the algorithm in LiDAR point cloud data extraction for building contour lines $[18,19]$; in postearthquake building loss analysis, scholars proposed a building shape analysis model based on ground-based LiDAR data, which effectively solved the problems of building contour polygon sequence extraction, shape discrete parameter extraction, irregular building block division, and earthquake damage analysis $[20,21]$. In terms of judging the degree of postearthquake building damage in the regional spatial context, scholars proposed a model based on texture extraction and fuzzy system analysis of postearthquake airborne LiDAR data, which effectively solved the problem of judging the degree of postearthquake building damage [22].

Terrestrial laser scanning proves to be an accurate method for rapid earthquake damage assessment [23]. The use of TLS to scan postearthquake buildings to obtain threedimensional point cloud data and quickly extract building earthquake damage information can provide technical support and scientific support for emergency rescue and damage assessment after the earthquake. Due to the functionality provided by the software accompanying the instrument, it does not meet the analysis needs of specialized technical modules for specific industries. MATLAB contains a large set of computational algorithms, image processing, and other advantages, so in order to solve the quantitative analysis of buildings, this paper uses the alpha shapes algorithm in the MATLAB platform to create a triangular network vector model (TIN-shaped model) to meet the building seismic information extraction and analysis needs. The model enables the extraction and measurement of LiDAR data characteristics of buildings after the earthquake, including the amount of tilt deformation of the building wall and the length, width, and depth of the wall cracks.

In this paper, we use the postearthquake building data from the 2013 Sichuan Lushan earthquake collected by a Trimble GX200 3D laser scanner as example data to validate the functionality of the building damage information extraction and analysis model. The research data in this paper was collected by the author's research team in the first time after the 2013 Lushan earthquake and is one of the few sets of foundation LiDAR data covering the full range of postearthquake building types in the region, with the data information mainly including different damage levels of different structural types of buildings. The modeling analysis of this data provides a scientific basis for establishing the earthquake damage matrix of buildings in the region.

\section{Data Sources}

According to China Earthquake Network (CENC), on April 20, 2013, an earthquake of magnitude Ms7.0 occurred in Lushan County, Sichuan Province (latitude 30.3 north, longitude 103.0 east), with a source depth of $13 \mathrm{~km}$. A total of 196 people were killed, 21 missing, 13,486 injured, about 630,000 people evacuated outdoors, and a large number of houses damaged as a result of the powerful 7.0 magnitude "4.20" earthquake in Lushan, Sichuan Province [24]. As of 8: 00 on the 28th, Sichuan Province, Lushan " 4.20 " 7.0 magnitude strong earthquake recorded a total of 5531 aftershocks, of which 113 aftershocks above 3.0 magnitude, including 4 of 5.0-5.9 magnitude, 21 of 4.0-4.9 magnitude, and 88 of 3.0-3.9 magnitude [25]. Lushan County is located in the southern section of the Longmenshan front tectonic zone. The Longmenshan fracture zone is located on the eastern edge of the Qinghai-Tibet plateau, and this is another devastating earthquake in the Longmenshan fracture zone, five years after the 2008 Wenchuan 8.0 magnitude earthquake [26].

The author's research team entered the seismic area in August 2013 and used a Trimble GX200 3D laser scanner (Table 1 for technical specifications) to collect LiDAR data from buildings in zones VII, VIII, and IX (Figure 1), with a total of 65 stations (Table 2). In the process of data acquisition, in order to improve the efficiency of each building using angled scanning, that is, the front and side of the building at the same time and in order to reduce the coordinate error, the form of relative coordinates, that is, the three-dimensional laser scanner is located at the point of control point coordinates.

\section{Data Preprocessing}

TLS enables rapid scanning of target objects, using this method to detect details that cannot be detected by airborne radar and remote sensing images; TLS can accurately measure deformation and damage to building structures (including shear cracks in building walls, wall shedding, and damage to load-bearing members). Additional measurements such as wall slope, spatial distribution of cracks, volume and position change calculations, and more can also be obtained. An important extension of this application is the use of TLS to scan seemingly safe buildings after an earthquake to ensure that there are no significant deformations that may not be visually detectable [27]. 
TABLE 1: Trimble GX200 technical specifications.

Technical specifications

Scanning distance

Scanning standard deviation

Target capture

Leveling

Scanning resolution

Scanning speed

Single point accuracy

Surface accuracy of modeling

Data integrity

Spot size for autofocusing
Parameters

Standard: $200 \mathrm{~m}$; lengthen: $350 \mathrm{~m}$ (w/OverScan)

$1.4 \mathrm{~mm} @ \leq 50 \mathrm{~m}: 2.5 \mathrm{~mm} @ 100 \mathrm{~m}$

Standard deviation: $<1 \mathrm{~mm}$ (trimble object)

Round vials in three-legged pedestals: 8'; biaxial compensator \pm 6' real-time automatic leveling compensation

Spot size: $3 \mathrm{~mm} @ 50 \mathrm{~m}$

Highest 5000 point/second

Location=12 mm @100 m; distance=7 mm @ 50 m;

Horizontal angle $=12 "(60 \mu \mathrm{rad})$; vertical angle $=14$ " $(70 \mu \mathrm{rad})$.

$\pm 2 \mathrm{~mm}$ (depends on the modeling approach)

Periodic zero index calibration; real-time temperature compensation.

$0.3 \mathrm{~mm} @ 5 \mathrm{~m} ; 0.9 \mathrm{~mm} @ 15 \mathrm{~m} ; 1.5 \mathrm{~mm} @ 25 \mathrm{~m}$

Point spacing; lowest $3.2 \mathrm{~mm} @ 100 \mathrm{~m}$ (Average $1.6 \mathrm{~mm}$ vertical = 18 point $/ \mathrm{cm}^{2} / 105$ point $/$ square inch)

Scan line (level): 200,000 points; scan line (upright): 65,536 points

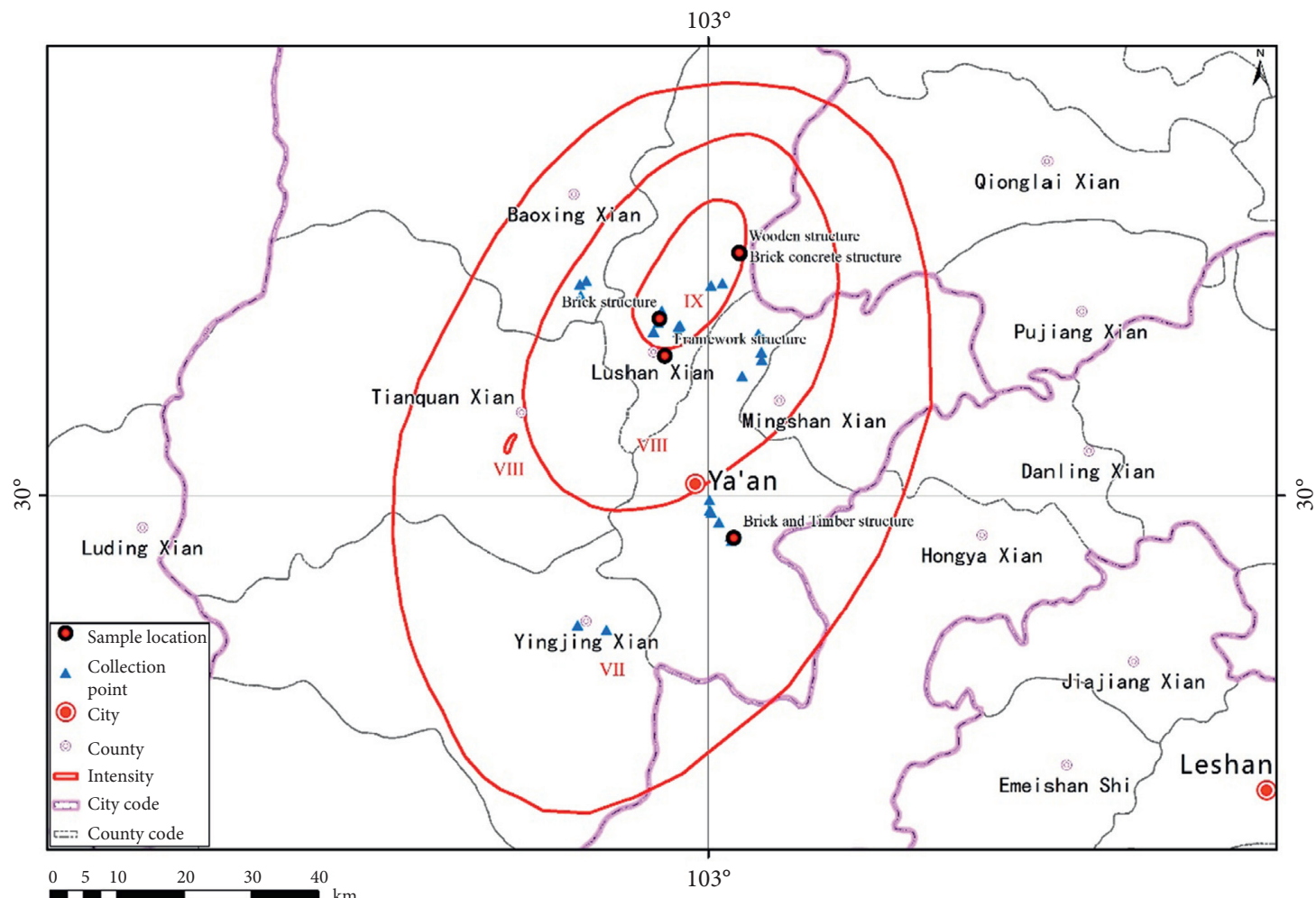

Figure 1: Distribution of survey points and sample examples.

TABLE 2: The type and number of the building.

\begin{tabular}{lc}
\hline Type of building structure & Number of samples \\
\hline Wooden structure & 13 \\
Brick and timber structure & 20 \\
Brick structure & 13 \\
Brick concrete structure & 16 \\
Framework structure & 3 \\
\hline
\end{tabular}

The raw data collected by TLS on the building surface mainly include $X / Y / Z$ spatial location information (columns 1-3), reflected intensity (column 4), RGB information (columns 5-7), and $X / Y / Z$ normal line information (columns 8-10) (Figure 2). The instrument's supporting software can view the seismic information such as cracks, shedding, and tilt deformation of the wall data collected, but the quantitative analysis is insufficient to meet the needs of the industry technical analysis.

In the process of data processing, the most critical thing is coordinate conversion. Since the data are collected in relative coordinates of the instrument and are collected in millimeters, errors are made in the reading of the data by the program, and the authenticity of the data is not presented and information on the characteristics of the seismic damage 


\begin{tabular}{|c|c|c|c|c|c|c|c|c|c|}
\hline 1 & 2 & 3 & 4 & 5 & 6 & 7 & 8 & 9 & 10 \\
\hline 1X coord. $x$ & - $\mid \mathbb{X}$ coord $Y$ & - 12 coord. $z$ & F S S Scalar & - $O$ Red (0.255) & - Verreen (0.255) & - Sive (0.255) & in & - In Ny & 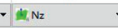 \\
\hline 988532.62 & 517064.86 & 103767.65 & 21 & 151 & 145 & 163 & -0.56 & -0.78 & -0.28 \\
\hline 988529.56 & 517069.48 & 103748.04 & 20 & 229 & 238 & 253 & -0.17 & -0.99 & 0.04 \\
\hline 98853261 & 517005.00 & 103726.82 & 17 & 255 & 255 & 255 & -0.17 & .0 .99 & 0.04 \\
\hline 988533.78 & 517006.32 & 103700.75 & 18 & 248 & 249 & 255 & -0.17 & .0 .99 & 0.01 \\
\hline 988533.77 & 517063.38 & 103660.16 & 15 & 248 & 249 & 255 & -0.17 & -0.99 & -0.01 \\
\hline 988533.81 & 517063.39 & 103665.95 & 19 & 244 & 245 & 254 & -0.17 & -0.99 & 0.01 \\
\hline 988531.52 & 517066.86 & 10364597 & 14 & 250 & 248 & 255 & -0.20 & -0.98 & 0.01 \\
\hline 98853329 & 5170642.28 & 103625.43 & 14 & 249 & 250 & 255 & -0.20 & .0 .98 & 0.01 \\
\hline 988532.61 & 517005.35 & 103604.61 & 15 & 244 & 244 & 255 & -0.20 & -0.98 & 0.01 \\
\hline 988534.19 & 517063.07 & 103584,50 & 17 & 242 & 248 & 255 & -0.17 & -0.99 & -0.01 \\
\hline 988534.11 & 517063.25 & 103564.33 & 11 & 249 & 250 & 255 & -0.17 & -0.99 & 0.01 \\
\hline 988535.12 & 517061.80 & 103543.58 & 16 & 249 & 250 & 255 & -0.17 & -0.99 & 0.01 \\
\hline 988533.67 & 517064.02 & 103523.67 & 18 & 249 & 250 & 255 & -0.17 & -0.99 & 0.01 \\
\hline 988533.95 & 517063.91 & 103503,46 & 15 & 248 & 251 & 255 & -0.20 & -0.98 & -0.01 \\
\hline 988533.79 & 517063.97 & 103482.93 & 16 & 247 & 249 & 255 & -0.20 & -0.98 & -0.01 \\
\hline 988529.87 & 517069.85 & 103463.67 & 15 & 248 & 249 & 255 & -0.20 & .0 .98 & -0.01 \\
\hline 98853286 & 517065.46 & 103442.97 & 16 & 255 & 255 & 255 & -0.19 & .0.98 & 0.04 \\
\hline 988534,42 & 517063.20 & 103422.54 & 18 & 248 & 249 & 255 & -0.22 & -0.97 & 0.04 \\
\hline 988537.21 & 517059.11 & 103401.53 & 15 & 255 & 255 & 255 & -0.22 & -0.97 & 0.01 \\
\hline 988532.87 & 517065.64 & 103382.12 & 15 & 254 & 246 & 255 & -0.20 & -0.98 & -0.01 \\
\hline
\end{tabular}

Figure 2: Raw LiDAR data for building walls.

is concealed. Point cloud denoising, filtering, coordinate conversion, etc., are performed through the basic functions provided by RealWorks software. The raw data is extracted as a separate wall, the lower left corner of the defined wall point cloud data is the starting point (0.0.0) of the origin coordinate $X / Y / Z$, and the processed data is transferred according to the specification in meters, where $X$ is the horizontal coordinate, $Y$ is the vertical coordinate, and $Z$ is the deformation value (Figure 3).

\section{Methods}

In order to give full play to the advantages of high-precision LiDAR data, a new method for building plane shape feature recognition (TIN-shape) is proposed based on the TIN triangulation network model, using LiDAR data obtained from TLS in combination with the alpha shapes algorithm to meet the special needs of the earthquake industry in extracting building damage information after an earthquake. Applying the new method to the identification and extraction of damage characteristics of different building structure types after the earthquake (wooden structure, brick structure, brick-wood structure, brick concrete structure, and framework structures) has obvious effects, which can measure the length and width of building cracks, extract the amount of wall tilt deformation, calculate the depth of wall cracks, count the number of point clouds, point spacing, etc. In the wood-frame building data collection and model application, the point cloud data at the load-bearing components of wood-frame houses is not well extracted due to the influence of building characteristics and the randomness of residents' self-built houses and therefore is not applied in this model.

In the process of the construction of this analytical model, contour drawing and color rendering of the loaded raw data is performed by meshgrid function to achieve the qualitative analysis of wall tilt deformation and crack positioning, slope vector analysis of the raw data by the gradient function to find the crack breaking direction, while the extraction of crack length, width, and depth and section drawing is achieved by the box selection measurement function. Alpha shapes algorithm picks up the effective boundaries of the wall point cloud data and creates the TINshaped model in this paper in combination with Delaunay triangle splitting function. The TIN-shaped model relies on point cloud data to build irregular triangular mesh surface, and through the TRI drawing function, the three-dimensional visual rendering of irregular deformation of the wall surface can be realized, so that quantitative analysis of the wall tilt deformation, cracks, wall shedding, and other shock information can be performed. The workflow of the analysis model is shown in Figure 4. follows:

The specific algorithm flow of alpha shapes [28] is as

(1) From the point set $A$, arbitrarily select a point $B_{1}\left(x_{1}, y_{1}\right)$ to start, with which the distance is less than $\alpha$ points to form a new point set $A_{2}$. From $A_{2}$, arbitrarily select a point $B_{2}\left(x_{2}, y_{2}\right)$, and the center of the circle $B_{3}\left(x_{3}, y_{3}\right)$ past points $B_{1}$ and $B_{2}$ is derived from equations (1) and (2).

(2) Iterative $A_{2}$, together with other points (except $B_{1}$ and $B_{2}$ ) to $B_{3}$ distance $D$. (a) If all $D$ is greater than radius $\alpha$ and there are no other points within it, points $B_{1}$ and $B_{2}$ can be judged to be edge contour points and $B_{1}$ and $B_{2}$ to be boundary line segments. (b) If there are other points in the circle when the value of $D$ is smaller than the radius $\alpha$, it can be judged not to be the edge contour point, stop iterating and go to (3).

(3) Select the next point in $A_{2}$ and follow steps (1) and (2) until all points in $A_{2}$ are judged.

(4) Take the next point in $A$ and judge in steps (1), (2), and (3) until all points in $A$ are judged. 


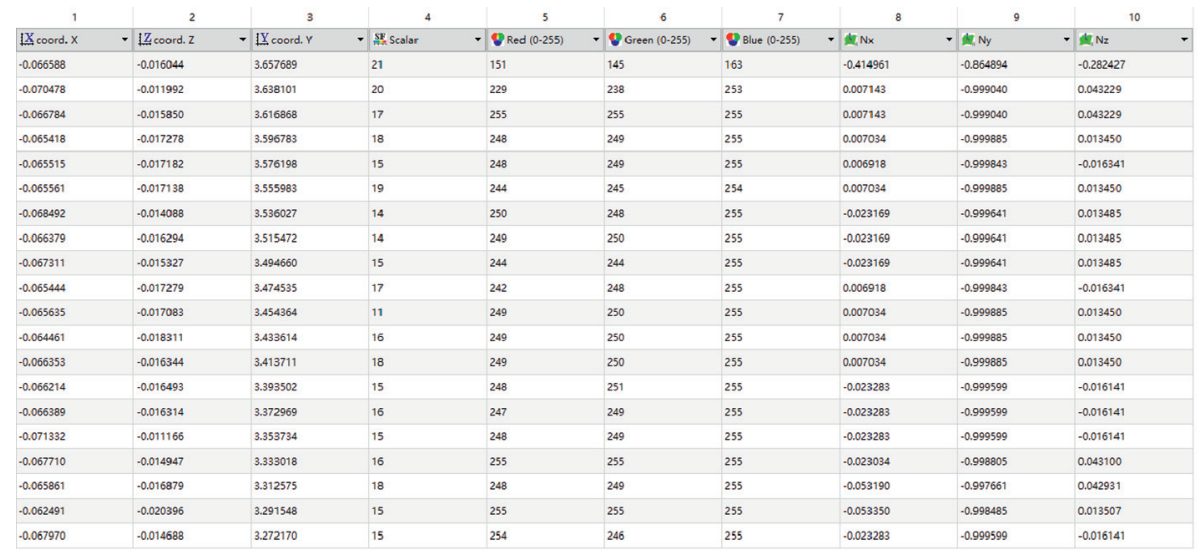

FIgURE 3: Converted data with coordinates.

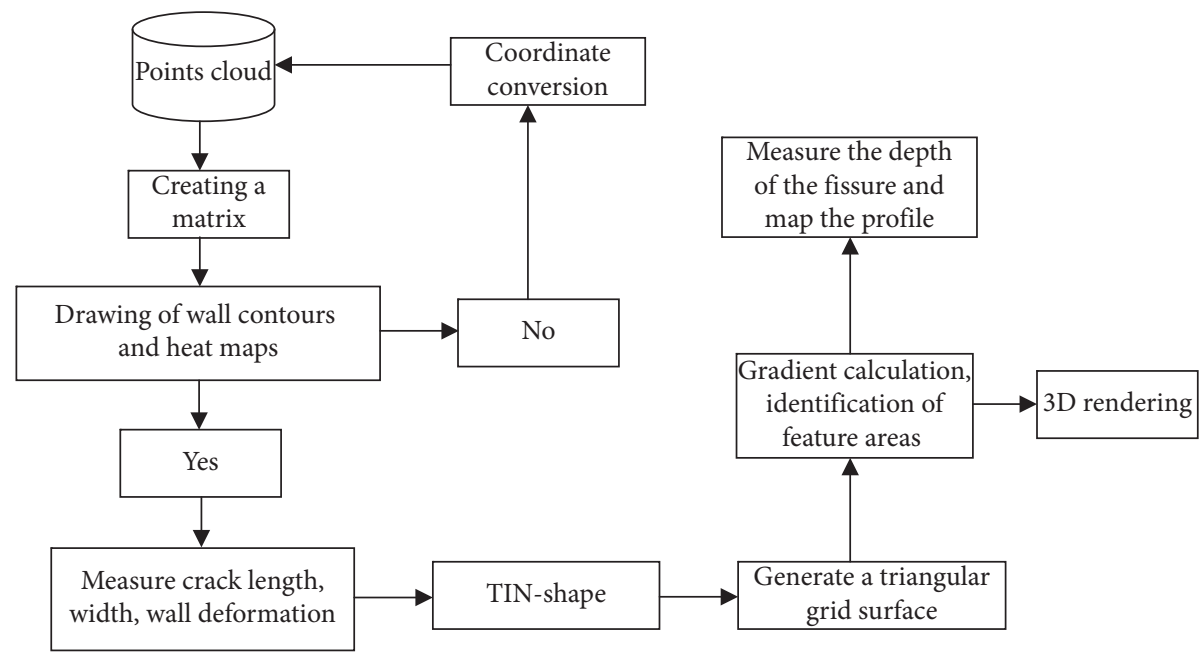

Figure 4: Analytical model workflow diagram.

$$
\begin{aligned}
& \left\{\begin{array}{l}
x_{3}=x_{1}+\frac{1}{2}\left(x_{2}-x_{1}\right)+H\left(y_{2}-y_{1}\right), \\
y_{3}=y_{1}+\frac{1}{2}\left(y_{2}-y_{1}\right)+H\left(x_{1}-x_{2}\right),
\end{array}\right. \\
& \left\{\begin{array}{l}
H=\sqrt{\frac{\alpha^{2}}{S_{B_{1} B_{2}}^{2}}-\frac{1}{4}} \\
S_{B_{1} B_{2}}^{2}=\left(x_{1}-x_{2}\right)^{2}+\left(y_{1}-y_{2}\right)^{2} .
\end{array}\right.
\end{aligned}
$$
(1).

Here, $H$ and $S$ are the variable description of equation

\section{Example Analysis}

The building seismic damage information extraction and analysis model has eight functional modules (Figure 5), whose main functions include loading of raw point cloud data (Figure 5(a)); determination of wall tilt deformation (Figure 5(b)); measurement of wall crack length, width, and depth; wall crack deformation direction (Figure 5(c)); wall point cloud data profile (Figure 5(e)); wall point cloud TIN triangle network crack identification (Figure 5(d)); threedimensional visualization of wall point cloud data (Figure 5(f)); and data accuracy analysis (point cloud count, point spacing, wall deformation value analysis). The model supports open data formats including ${ }^{*}$.asc, ${ }^{*}$.txt, ${ }^{*}$.xyz, and * .las.

In order to verify the validity of the analytical model, five sets of sample data were selected in this paper according to the type of structure sampled from the buildings, including wooden structure, brick-wood structure, brick structure, brick-concrete structure, and frame structure [9]. The acquisition of high-precision data from TLS provides technical assistance in extracting destructive features that have small deviations and cannot be identified by the naked eye.

Wooden structure (Figure 6(a)): the building is located in the IX-degree area of the earthquake and is a self- 


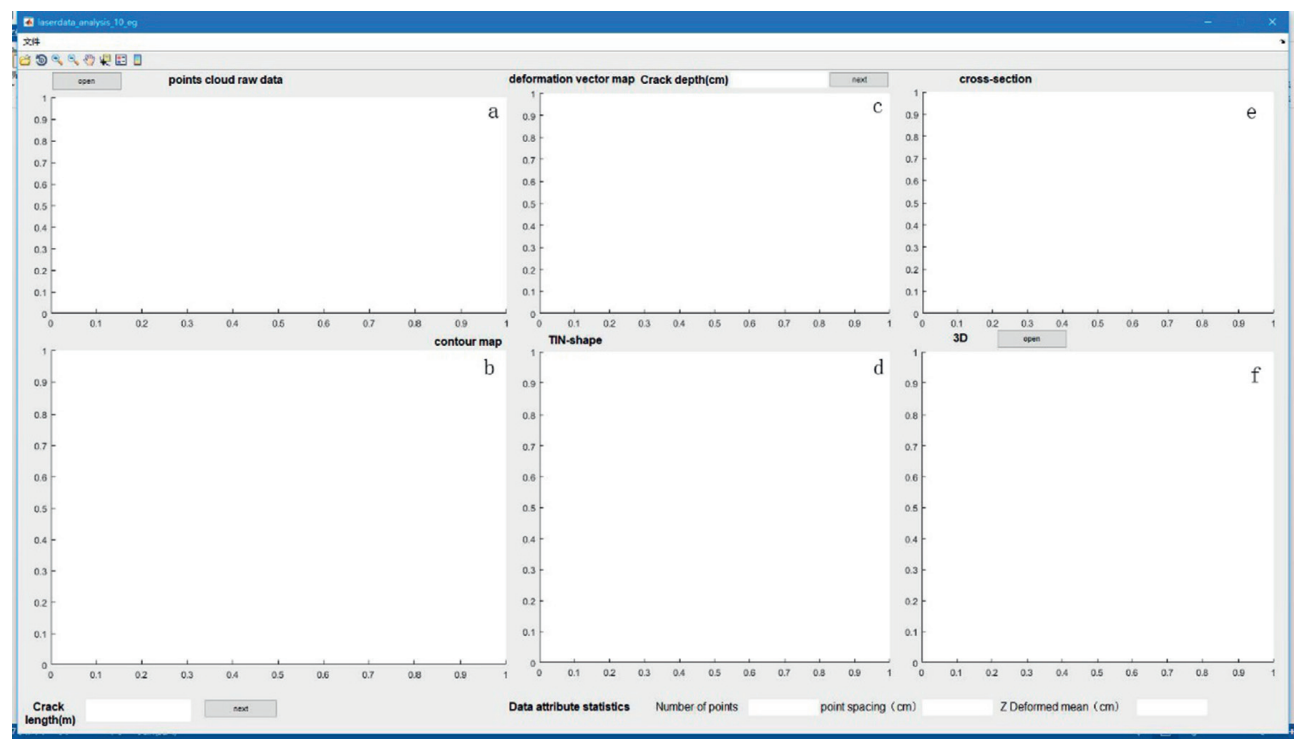

FIgURE 5: Analytical model interface.

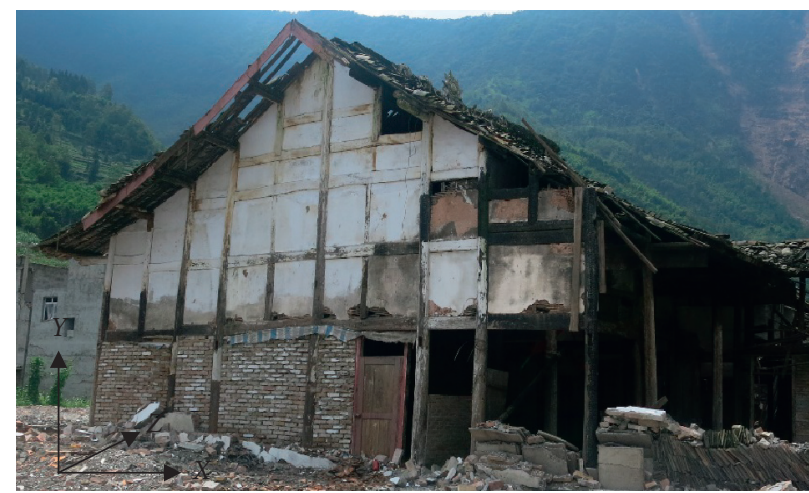

(a)

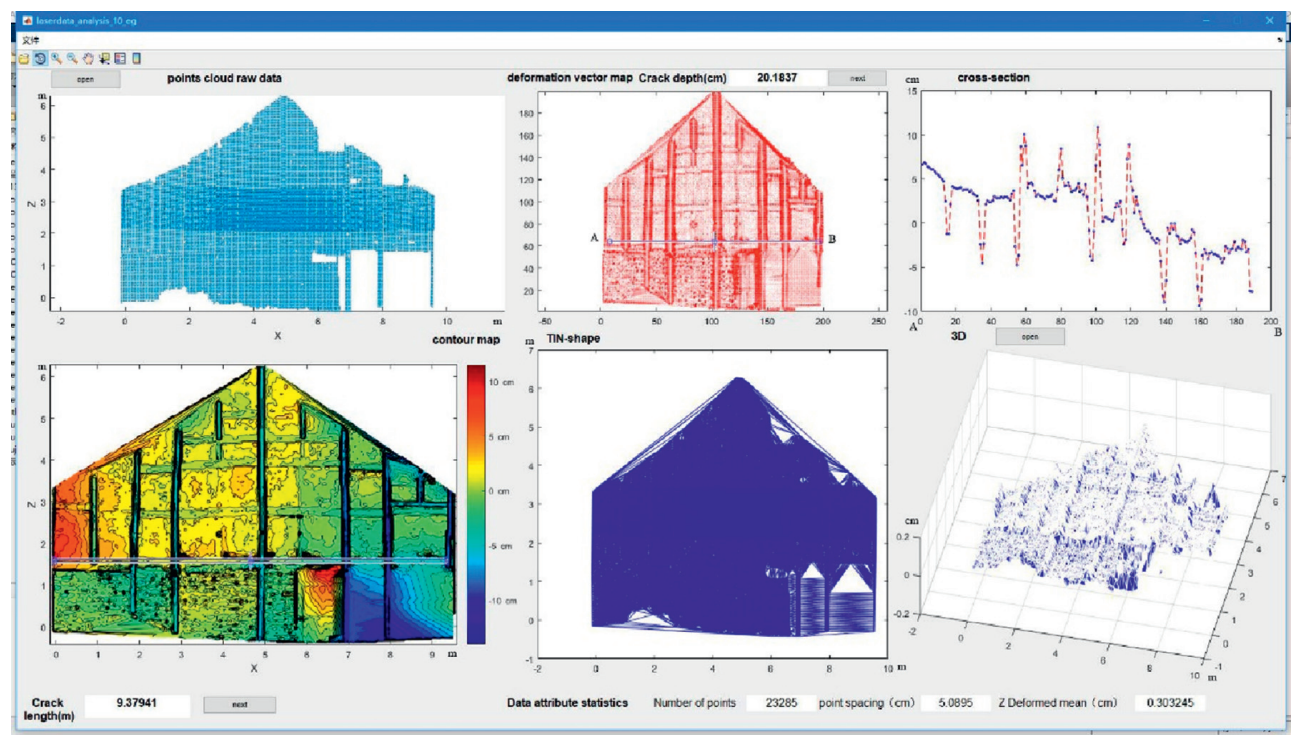

(b)

Figure 6: Continued. 


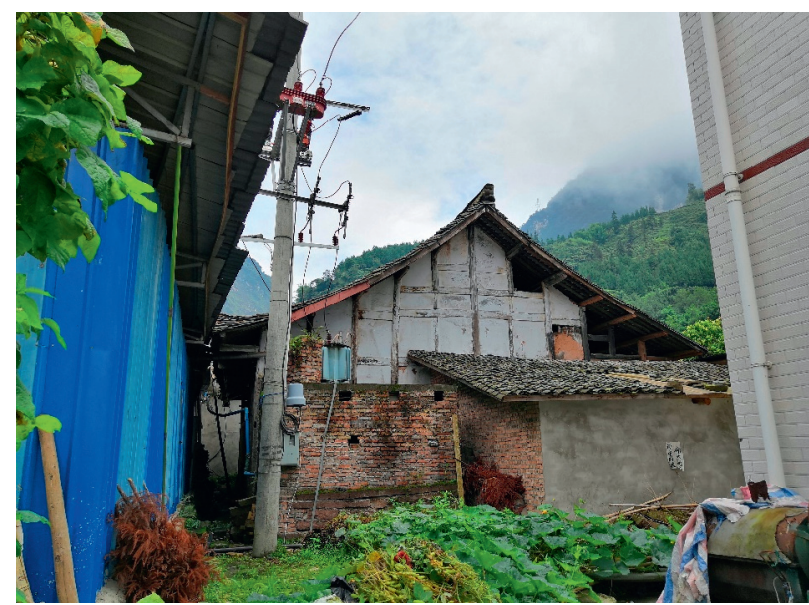

(c)

FIgURE 6: (a) Wooden construction. (b) Information extraction of wooden construction. (c) Wooden construction of 2019.

built house of local residents with wooden beams and columns as load-bearing members. The building is divided into four categories in terms of the main material: the main timber frame structure, one floor of infill brick walls, more than one floor of board infill walls, and a roof of wooden.

By setting the bottom left corner of the wall as the origin coordinates to analyze the sample data, there are 23,285 points in this set of point cloud data; the spacing between points is about $5.08 \mathrm{~cm}$; the average tilt deformation of the wall is about $0.3 \mathrm{~cm}$; the model analysis of the LiDAR data of the building concluded that the architectural integrity of the structure is better. The model analysis of the building's LiDAR data shows that the structure has good architectural integrity, and the wooden architecture as the main structure is less damaged in the earthquake; as an infill wall, one layer of the brick masonry has collapsed, more than one layer of the wooden board infill wall is well preserved, and the roof tiles have fallen off; due to the unevenness of the wall infill, the difference between the wall and the wooden columns is slightly larger. In the main structure, the wooden columns are not planed with the wooden beams and walls, so in the contour distribution diagram, the difference between the wooden columns and the walls is more obvious, but from the analysis of the vertical integrity of the wooden columns up and down, the wooden columns do not tilt (Figure 6(b)). In 2019, the author returned to the site of that year's earthquake for data verification and the house still exists (Figure 6(c)). One wall of the wood-framed house could not be photographed because it was obscured by the later construction of the new house. The building has no obvious signs of damage to the load-bearing elements through data analysis, and the infill wall has the phenomenon of collapse, and its damage level is low.

Brick and wood construction (Figure 7): the building is located in zone VII of the earthquake and is a local resident's self-built house. Its architectural features include uneven plastering on the walls, brick wall masonry, no seismic-resistant structural measures, and a wooden beam and tile roof.

The lower left corner of the wall is set as the origin coordinates to analyze the sample data, and there are 7693 points in the point cloud data; the distance between the points is about $5.7 \mathrm{~cm}$; the average value of the tilt deformation of the wall is about $-0.55 \mathrm{~cm}$ (Figure 7(b)). A slight deformation of approximately $3 \mathrm{~cm}$ to the outside of the screen occurred in the lower right-hand area of the wall, $B$, as a result of the model analysis. In the deformation zone $B$ and the left side of the wall in the middle of $A$, there is an obvious microcrack 1 , but the contour distribution diagram cannot be clearly shown, through the triangular network distribution diagram of the wall irregular areas of the identification, combined with the wall gradient drawing profile method to identify the crack 1 on both sides of the wall mismovement of about $0.5 \mathrm{~cm}$ (Figure $7(\mathrm{a})$ ). The building has no obvious signs of damage to the load-bearing elements through data analysis, and there are minor cracks on the walls, and its damage level is low.

Brick structure (Figure $8(\mathrm{a})$ ): the building is located in the IX zone of the earthquake and is a two-storey house built by local residents themselves. Its architectural features: low construction costs, no seismic structural measures, load-bearing walls of brick masonry, no reinforced concrete columns and beams, and the roof is prefabricated.

The sample data were analysed with the lower left corner of the wall as the origin coordinates, and the point cloud data consisted of 11,978 points; the distance between the points was about $5.5 \mathrm{~cm}$; the average value of the tilt deformation of the wall was about $-0.25 \mathrm{~cm}$. The seismic damage information extracted from the model matched the actual damage, and quantitative 


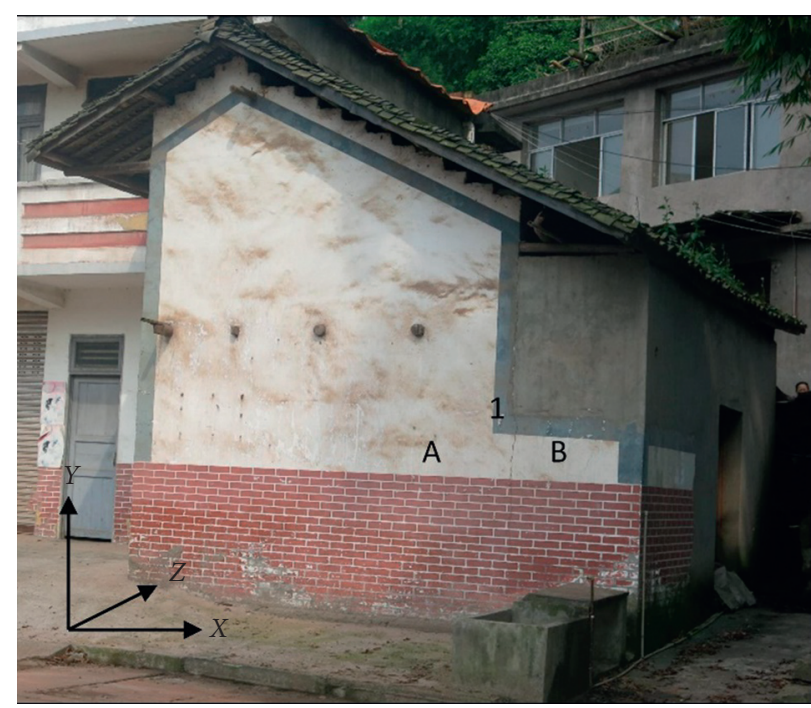

(a)

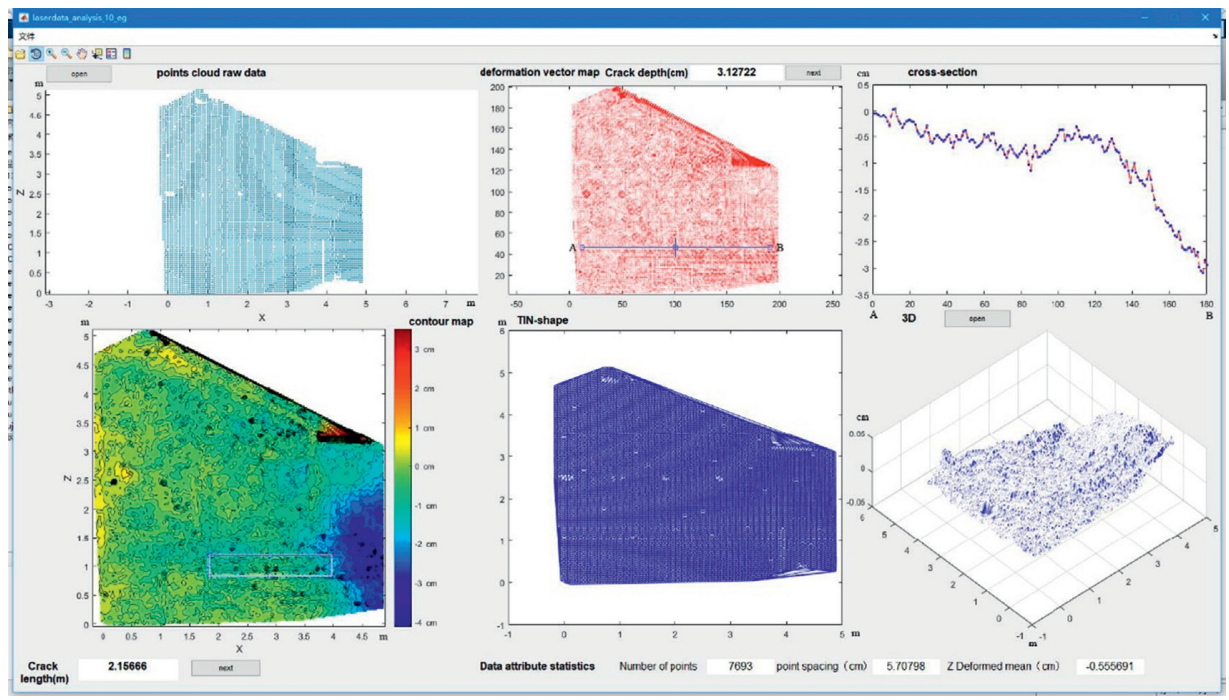

(b)

FIGURE 7: (a) Brick and wood construction. (b) Information extraction of brick and wood construction.

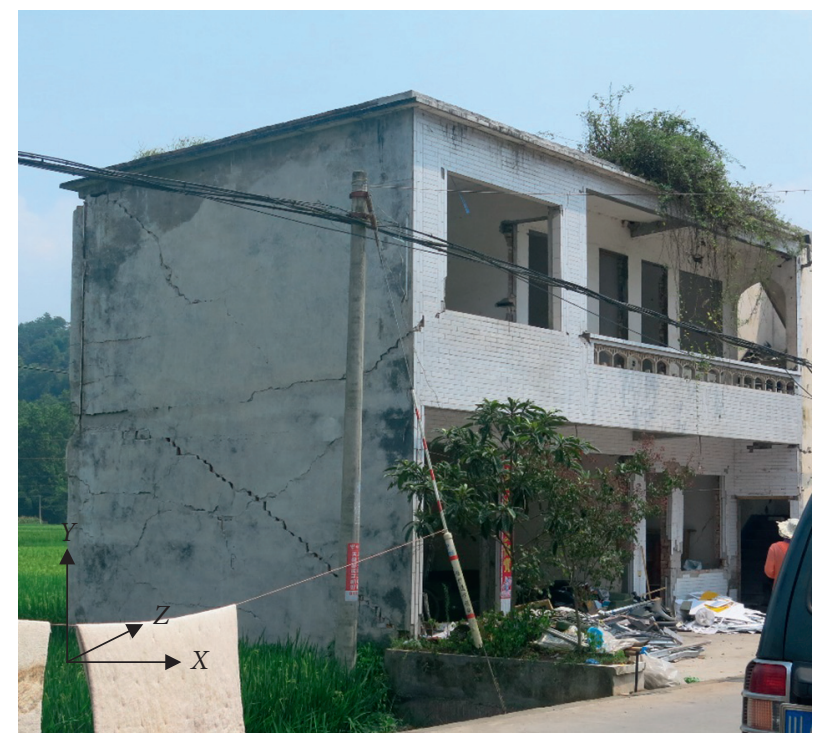

(a)

Figure 8: Continued. 


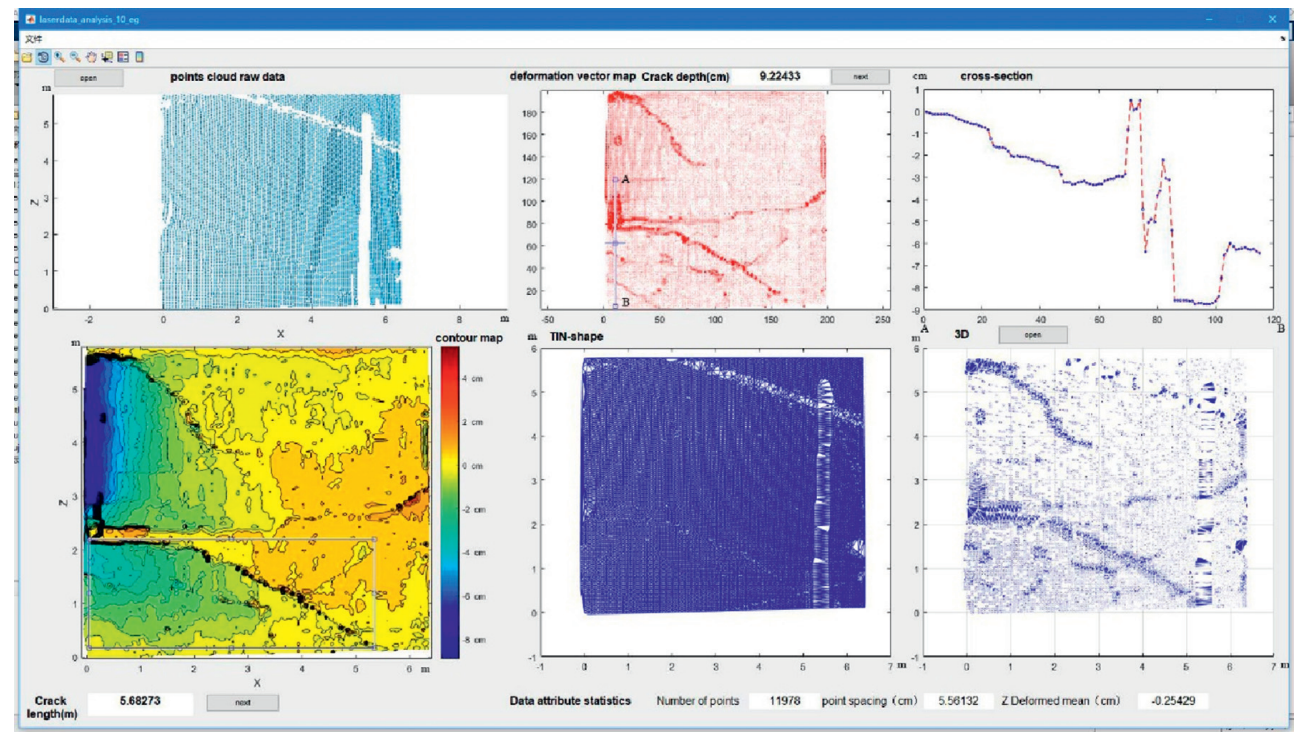

(b)
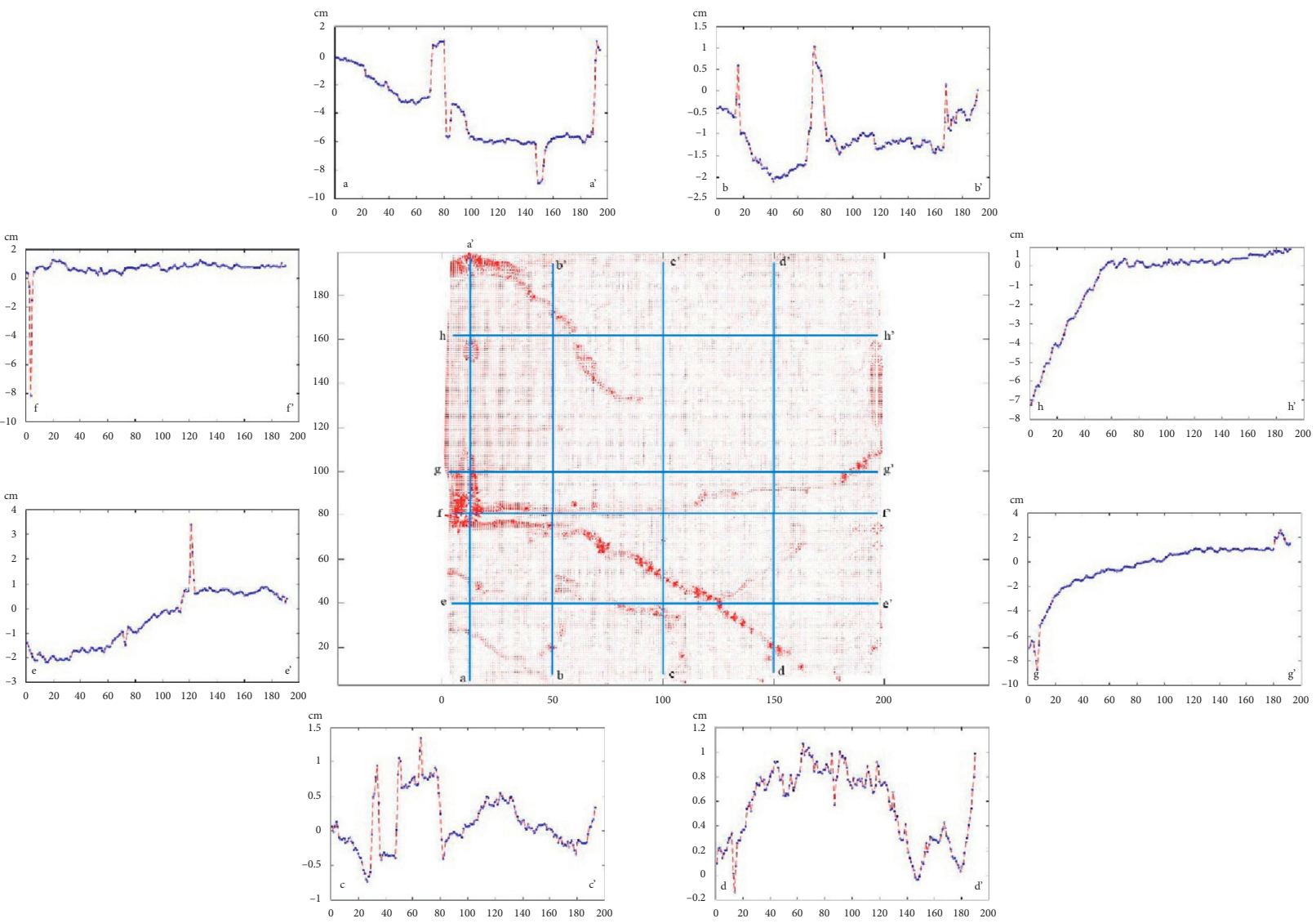

(c)

FIGURE 8: (a) Brick buildings. (b) Brick building information extraction. (c) Wall section of brick building.

analysis showed that the building was severely damaged, with walls leaning about $6 \mathrm{~cm}$ towards the screen on the left side of the second floor, and $X$-cracks and penetration cracks in the first floor walls, with the longest crack measured on site is about $5.8 \mathrm{~m}$, and the model calculated length is about $5.68273 \mathrm{~m}$
(Figure 8(b)). Since the TLS collects point cloud data of the building surface, the actual displacement mismovement of the walls on either side of the crack is calculated when the model extracts the crack depth of the building. The a-a' profile shows that the maximum crack depth of about $5.1 \mathrm{~cm}$ is located on the left side of 
the building where the first and second floors meet. Due to the obstruction by utility poles and wires, the TLS is missing local data in the data collection process. The results of the quantitative extraction and analysis of the seismic damage characteristics of the building by means of drawing profiles on the point cloud data are fully consistent with the field photo records (Figure 8(c)). The building showed obvious signs of damage to its load-bearing members through data analysis, with $X$ shaped penetration cracks in the walls, and its damage level is high.

Brick concrete structure (wall in red box in Figure 9(a)): the building is located in the IX-degree zone of the earthquake and is a three-storey house built by local residents with earthquake-resistant measures. Its architectural features are brick-mixed masonry structure, with structural columns in the corners of the walls and the wall bearing jointly, the roof of the first and second floors is reinforced concrete, with load-bearing beams and a large opening. Its seismic characteristics are more pronounced, with sloping deformation and $X$ cracks in the wall surface, which are serious damage.

Analysis of the sample data with the bottom left corner of the wall set to origin coordinates: for a total of 32,684 points in the point cloud data set, the point spacing is approximately $2.1 \mathrm{~cm}$; the average slope deformation of the wall is approximately $5.5 \mathrm{~cm}$; the contour distribution map shows that the wall surface is severely tilted and deformed, mainly by cracks 1 and 2 on the left side of the wall surface (Figure 9(b)), while the right side of the wall crack $B$ is tilted and deformed in the inner direction of the screen relative to the left side area $A$. The amount of deformation is about 7 to $8 \mathrm{~cm}$. Crack 3 at the top of the wall, where the sheathing is dislodged at the same time as the tilt deformation, with a maximum displacement of approximately $10 \mathrm{~cm}$; a cross-section of areas $A$ to $B$ at the bottom of the wall gives a displacement of approximately $6.31578 \mathrm{~cm}$ for crack 2 (Figure $10(\mathrm{e})$ ), the field measured length of crack 2 is about $1.25 \mathrm{~m}$, and the model calculated length is about $1.30931 \mathrm{~m}$; construction of a TIN-shaped model to normalize the amount of skewed deformation of point cloud data and identify the deformation region (Figures $10(\mathrm{~d})$ and 11). The point cloud data is based on the TINshaped model 3D visualization analysis (Figure 10(f)), which takes full advantage of the high accuracy of the point cloud data and makes the deformed area of the building more visual. The building showed obvious signs of damage to its loadbearing members through data analysis, with $X$ shaped penetration cracks in the walls, and its damage level is high.

Frame structure (Figure 12): the building is located in the VIII zone of the earthquake and is a reinforced concrete frame structure with seismic-resistant structural measures.
The lower left corner of the wall is set as the origin coordinates to analyze the sample data, and the point cloud data has 134,947 points; the spacing between the points is $3.9 \mathrm{~cm}$; the average value of the tilt deformation of the wall is about $3.5 \mathrm{~cm}$ (Figure 12(b)). The model extracted the seismic damage information of the building and concluded that the building has a piece of wall skin peeling off from the wall $7.55904 \mathrm{~m}$ wide and $10.9539 \mathrm{~m}$ high, field measurement width $8 \mathrm{~m}$, height $12 \mathrm{~m}$, the difference of the peeling area is about $8.48 \mathrm{~cm}$, and the main body of the building does not show any obvious deformation. A banner approximately $6 \mathrm{~m}$ long and $0.5 \mathrm{~m}$ wide in the area of the shed skin on the first floor of the building; the banner was attached to the wall of the building at a distance of approximately $1 \mathrm{~cm}$ between them (Figure 12(c)). The model is able to accurately extract the length, width, and distance of the banner from the wall when extracting and analyzing the point cloud data features. The above analysis further validates the accuracy of the extraction model in this study and its application in the extraction of postearthquake building damage information. The building was not tilted and deformed by the data analysis of its walls, and the wall adhesions fell off obviously, and its damage level is low.

\section{Summary and Discussion}

In this paper, ground-based LiDAR data are applied for the first time for the modeling and extraction of information on monolithic seismicity of buildings after an earthquake, which has the following advantages:

(1) The high accuracy of ground-based LiDAR data is fully utilized, and the TIN-shape model is constructed in conjunction with the alpha shapes algorithm, which solves the problem of small deviations in the extraction of building damage features after an earthquake, which cannot be identified by the naked eye

(2) Fast computing speed and suitable for tens of thousands of points of cloud data loading calculation

(3) In the five types of building structures sampled at the site of the Lushan earthquake, in addition to timberframe houses, they are applicable to buildings of brick-wood, brick-mix, frame, and shear structures

(4) With some flexibility, by adjusting the alpha value, it is possible to realize the interference of point cloud data vacancy areas such as doors and windows in the visualization process

(5) The construction of the model mainly addresses the specialized needs of the industry and addresses the quantitative analysis of deformation of buildings

(6) The GUI interactive interface is easy to operate, with a high degree of functional integration, and the analysis and extraction of relevant content can be completed in one operation 


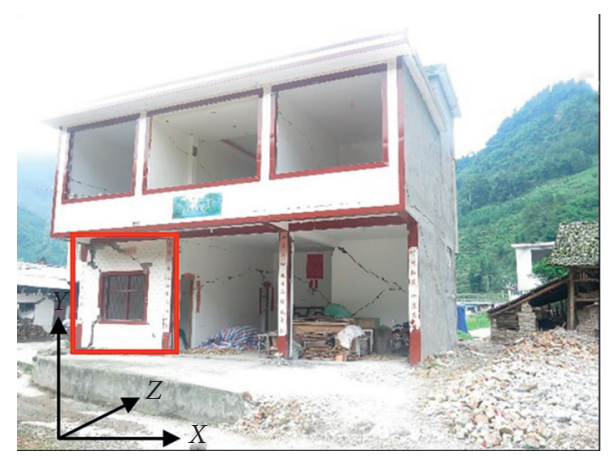

(a)

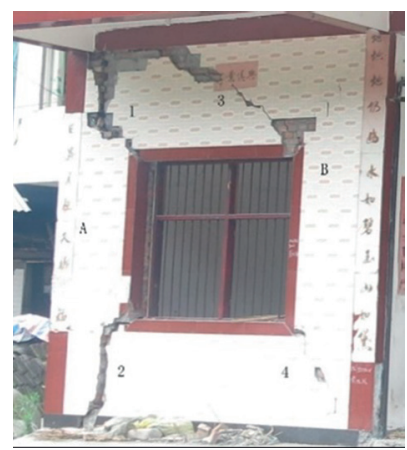

(b)

FIGURE 9: Brick and concrete buildings.

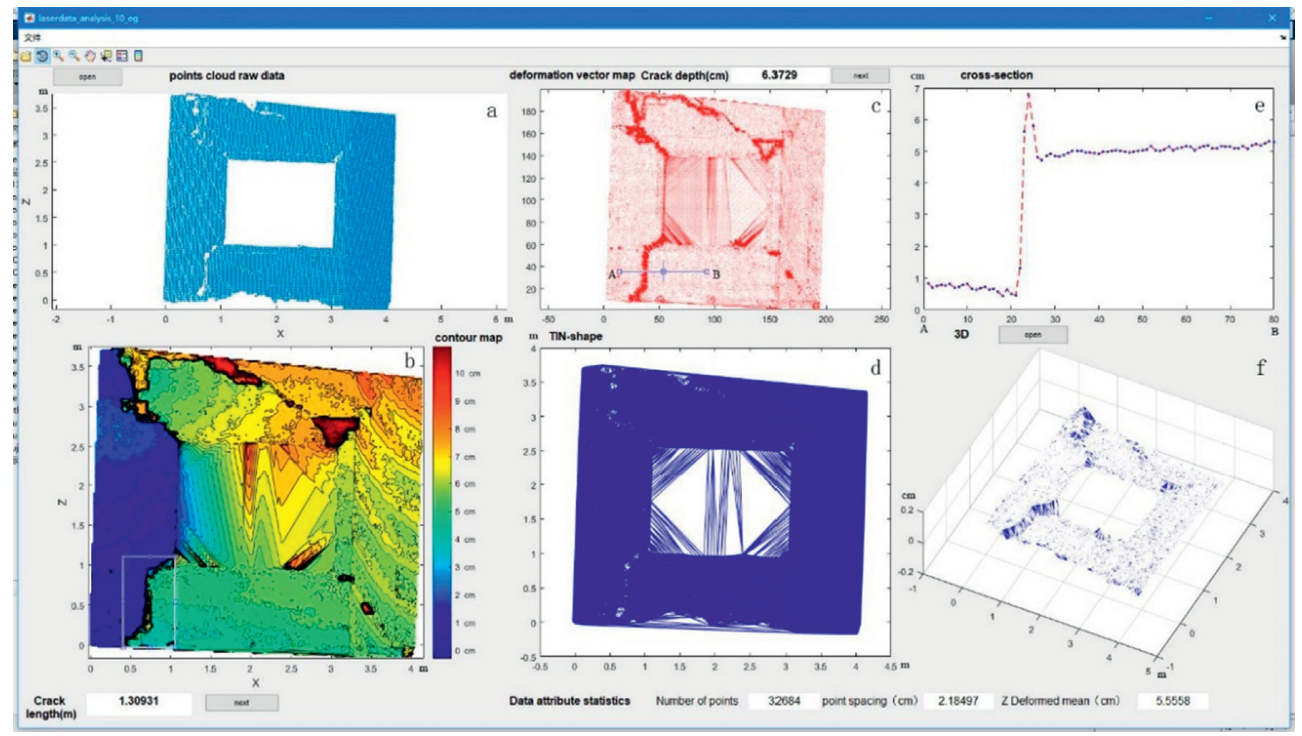

FIGURE 10: Building damage information extraction for brick and concrete structures.

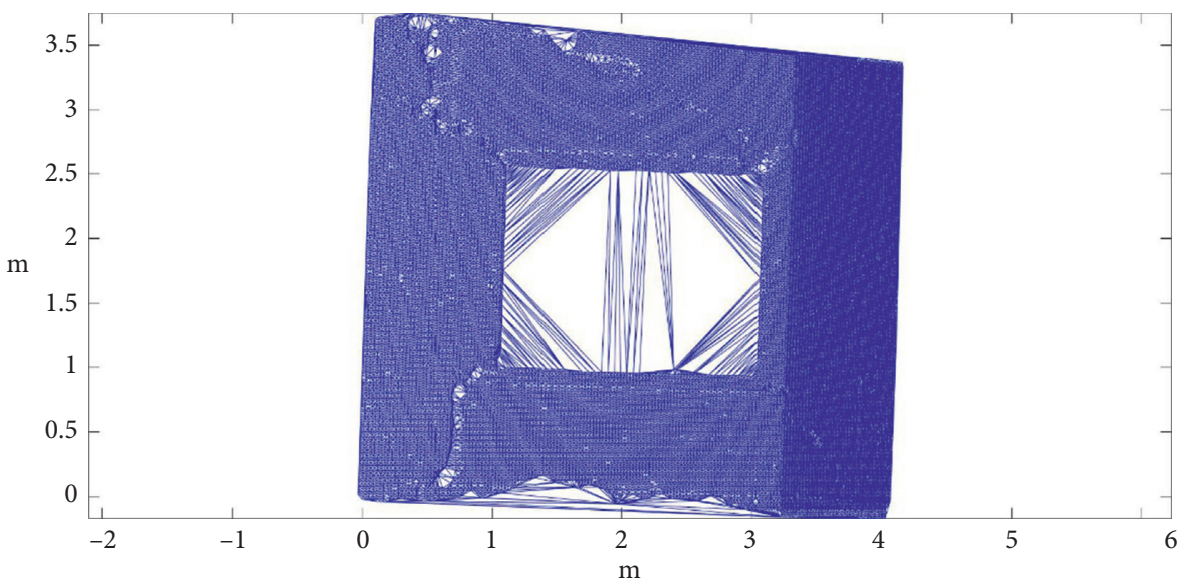

FIGURE 11: Distribution map of triangular network on brick and concrete construction walls.

(7) The point cloud data acquired by TLS provides data support for quantitative analysis of seismic damage information and building reinforcement and enhancement of seismic fortification capabilities
At present, there are few methods for extracting the information of single body damage of buildings after earthquake, and there is no better way to evaluate the accuracy of LiDAR data modeling and analysis of building 


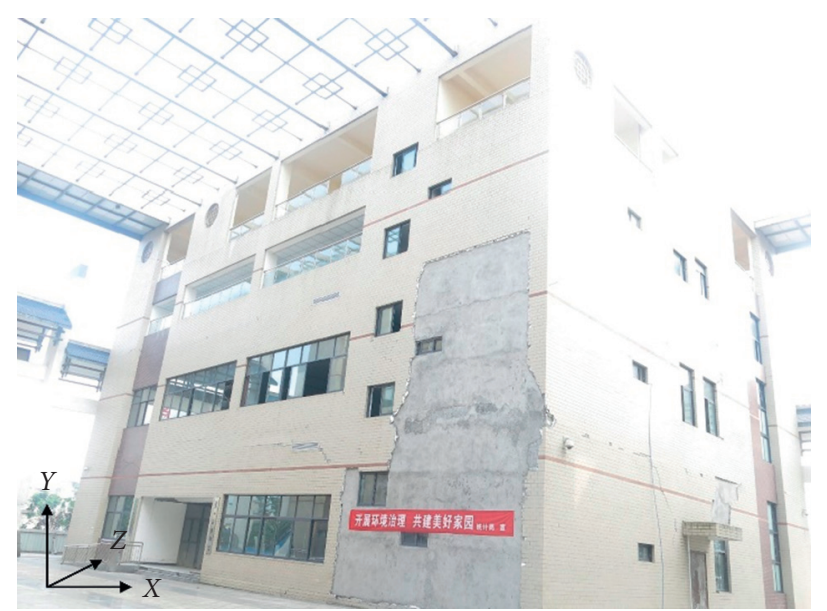

(a)

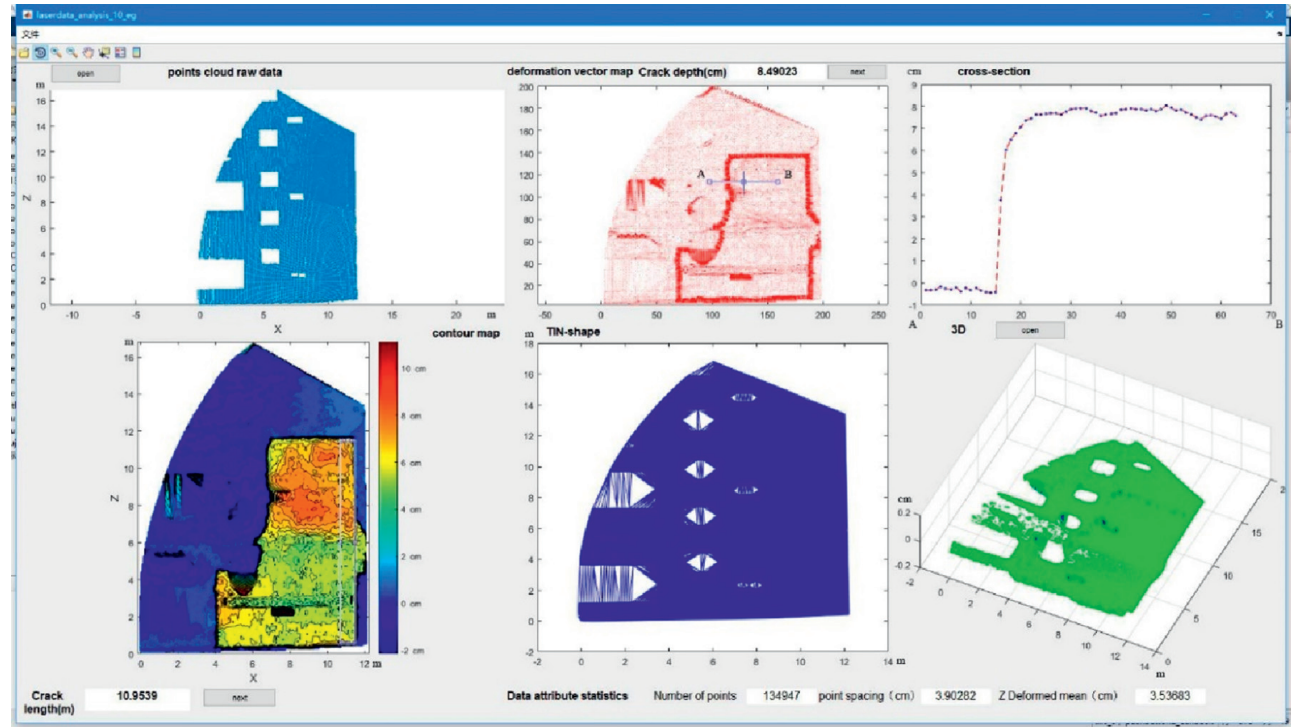

(b)
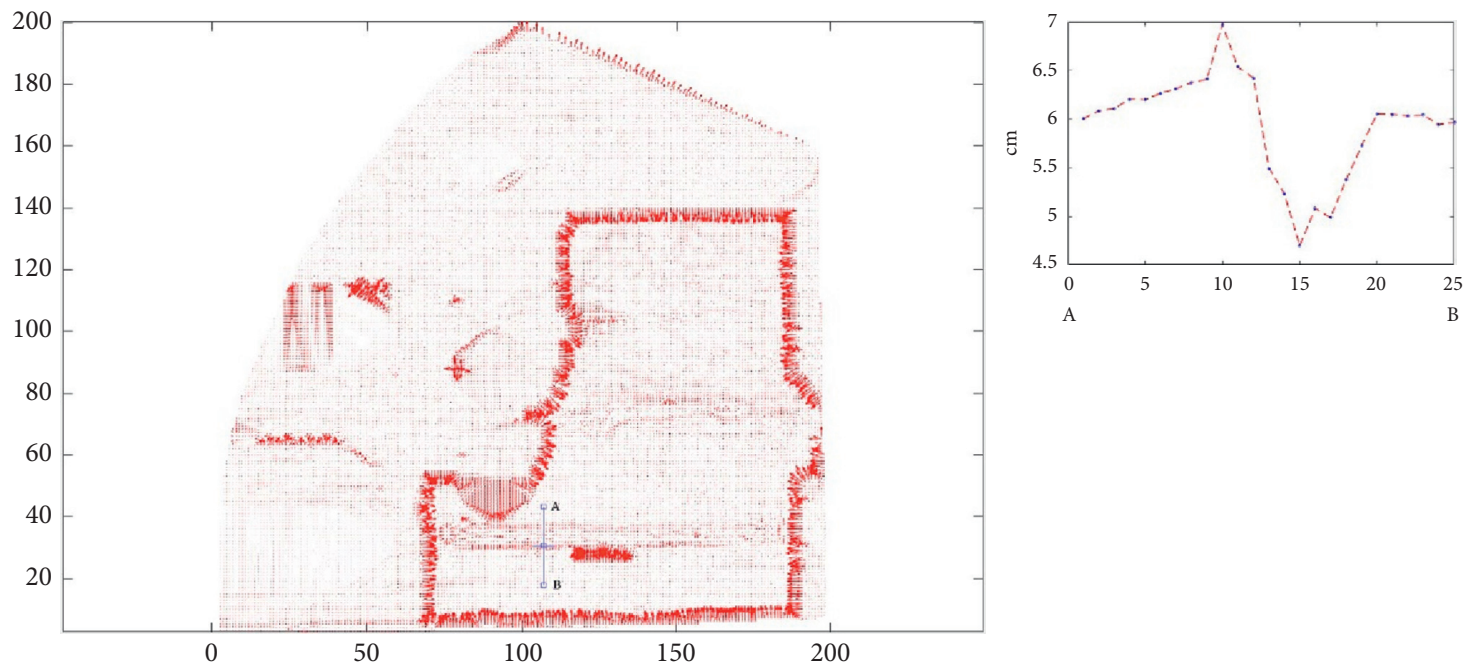

(c)

Figure 12: (a) Frame building. (b) Frame structure information extraction. (c) Banner-to-wall distance. 
foundations after earthquake. The TIN-shaped model is able to extract building seismic features with small deviations that cannot be identified with the naked eye.

The TLS collects the point cloud data of the building surface, so the calculated crack depth is actually the displacement mismovement of the walls on both sides of the crack.

In the extraction of seismic damage information for wood-frame buildings, the unevenness of the wall infill results in slightly larger differences between the wall surface and the load-bearing members, wooden beams, and columns, and the model is only able to determine whether there is tilt deformation in wood-frame buildings from the totality and is not able to identify detailed changes.

\section{Conclusions}

This paper presents a highly specialized solution for detecting tilt variables and cracking information in building walls using a laser scanning point cloud of a building. The proposed modeling approach requires low computational power, including point cloud data loading, tilt deformation volume analysis, profile analysis, and 3D modeling analysis. The model uses contour distribution diagrams to achieve the preliminary extraction of tilt variables and cracks in the building walls; the construction of the triangulation model and profile analysis to further extract the detailed changes in the walls; and the construction of the 3D model to visualize and analyze the overall morphology of the building walls. The results of the method confirm the effectiveness of the seismic damage information extraction of building walls, while showing detailed changes that are not easily identified by the naked eye. In the detailed variation extraction application, cracks as small as $5 \mathrm{~mm}$ can be identified.

\section{Data Availability}

The data used to support the findings of this study are available from the corresponding author upon request.

\section{Conflicts of Interest}

The authors declare that they have no conflicts of interest.

\section{Acknowledgments}

This study could not be carried out without the hard work of team members Mingzhen Wang, Xinke Feng, Zirui Li, and other comrades in the seismic areas of the hardship environment data collection. Although some of them have graduated, the results of this study are inseparable from their efforts and sweat, and the authors would like to thank them. At the same time, the authors thank Mr. Zhanyu Wei of the Institute of Geology China Earthquake Administration for his help and support in point cloud data processing; and development of guidelines for rapid emergency mapping; Innovative Research Team of Hebei Earthquake Agency for Research on Seimogenic Tectonics and Mechanisms of Strong Earthquake (project number: DZ20180319009); and China Earthquake Administration (CEA) Earthquake
Emergency Priority Tasks (project number: CEA_EDEM2020).

\section{References}

[1] J. Tu, H. Sui, W. Feng, and Z. Song, "Automatic building damage detection method using high-resolution remote sensing images and 3D gis model," ISPRS Annals of Photogrammetry, Remote Sensing and Spatial Information Sciences, vol. III-8, pp. 43-50, 2016.

[2] P. Z. Zhang, Q. D. Deng, Z. Q. Zhang, and H. Li, "Active faults, earthquake hazards and associated geodynamic processes in continental China," Science in China Series D-Earth Sciences, vol. 43, pp. 1607-1620, 2013, (in Chinese with English abstract).

[3] W. H. Zhou, H. Y. Qin, J. L. Qiu et al., "Building information modelling review with potential applications in tunnel engineering of China," Royal Society Open Science, vol. 4, no. 8, pp. 170-174, 2017.

[4] J. Qiu, X. Wang, S. He, H. Liu, J. Lai, and L. Wang, "The catastrophic landside in Maoxian county, Sichuan, SW China, on June 24, 2017," Natural Hazards, vol. 89, no. 3, pp. 1485-1493, 2017.

[5] J. L. Qiu, Y. L. Xie, H. B. Fan, Z. C. Wang, and Y. W. Zhang, "Centrifuge modelling of twin-tunnelling induced ground movements in loess strata," Arabien Journal of Geoscience, vol. 10, p. 493, 2017.

[6] J. L. Qiu, H. Q. Liu, J. X. Lai, H. Lai, J. Chen, and K. Wang, "Investigating the long term settlement of a tunnel built over improved loessial foundation soil using jet grouting technique," Journal of Performance Constructed Facilities, vol. 32, no. 5, 2018.

[7] X. Li, Z. Li, J. Yang et al., "Spatiotemporal characteristics of earthquake disaster losses in China from 1993 to 2016," Natural Hazards, vol. 94, no. 2, pp. 843-865, 2018.

[8] Z. Ye, Y. A. N. Jinxu, M. A. O. Li, and C. Lu, "Study on earthquake damage characteristics of buildings in the eastern boundary between Sichuan and Yunnan provinces," South china Journal of Seismology, vol. 37, no. 1, pp. 89-96, 2017.

[9] L. Zhang, B. Zhu, Z. Tao et al., "Field investigation and failure characteristics of buildings damaged by the 7.0-magnitude earthquake in Jiuzhaigou," China Earthquake Engineering Journal, vol. 41, no. 4, pp. 1053-1059, 2019.

[10] H. Yang, M. Omidalizarandi, X. Xu, and I. Neumann, "Terrestrial laser scanning technology for deformation monitoring and surface modeling of arch structures," Composite Structures, vol. 169, pp. 173-179, 2017.

[11] M. Makuch and P. Gawronek, "3D point cloud analysis for damage detection on hyperboloid cooling tower shells," Remote Sensing, vol. 12, no. 10, p. 1542, 2020.

[12] J. Markiewicz, S. Łapiński, P. Kot et al., "The quality assessment of different geolocalisation methods for a sensor system to monitor structural health of monumental objects," Sensors, vol. 20, no. 10, p. 2915, 2020.

[13] R. Li, "Research on building facade recognition and extraction based on terrestrial LiDAR Dat," Master's thesis, Jiangxi University of Technology, Nanchang, China, 2019.

[14] M. J. Olsen, F. Kuester, B. J. Chang, and T. C. Hutchinson, "Terrestrial laser scanning-based structural damage assessment," Journal of Computing in Civil Engineering, vol. 24, no. 3, pp. 264-272, 2010.

[15] P. Ziółkowski, "Remote sensing in laboratory diagnostics of reinforced concrete elements-current development and 
vision for the future," in Proceedings of the IRES 8th International Conference, August 2015.

[16] R. Nowak, R. Orłowicz, and R. Rutkowski, "Use of TLS (LiDAR) for building diagnostics with the example of a historic building in karlino," Buildings, vol. 10, no. 2, p. 24 , 2020.

[17] D. Li, J. Liu, L. Feng, Y. Zhou, P. Liu, and Y. F. Chen, "Terrestrial laser scanning assisted flatness quality assessment for two different types of concrete surfaces," Measurement, vol. 154, p. 107436, 2020.

[18] W. Shen, L. I. Jing, Y. Chen, L. Deng, and G. Peng, "Algorithms study of building boundary extraction and normalization based on LIDAR data," Journal of Remote Sensing, vol. 12, no. 5, pp. 692-698, 2008.

[19] D. Wang, W. Cheng, Y. Zheng, and H. Yue, "Mathematic morphology-based building edge detection under Matlab plat form," Science of Surveying and Mapping, vol. 35, no. 1, pp. 172-173, 2010.

[20] Q. Jiao, H. Jiang, and Q. Li, "Building earthquake damage analysis using terrestrial laser scanning data," Advances in Civil Engineering, vol. 2019, Article ID 8308104, 12 pages, 2019.

[21] H. Jiang, Q. Li, Q. Jiao, X. Wang, and L. Wu, "Extraction of wall cracks on earthquake-damaged buildings based on TLS point clouds," IEEE Journal of Selected Topics in Applied Earth Observations and Remote Sensing, vol. 11, no. 9, pp. 30883096, 2018.

[22] M. Janalipour and A. Mohammadzadeh, "Evaluation of effectiveness of three fuzzy systems and three texture extraction methods for building damage detection from post-event LiDAR data," International Journal of Digital Earth, vol. 11, no. 12, pp. 1241-1268, 2017.

[23] C. Vasilakos, S. Chatzistamatis, O. Roussou, and N. Soulakellis, "Terrestrial photogrammetry vs laser scanning for rapid earthquake damage assessment," ISPRS - International Archives of the Photogrammetry, Remote Sensing and Spatial Information Sciences, vol. XLII-3/W4, pp. 527-533, 2018.

[24] Y. Chen, Z. Yang, Y. Zhang, and C. Liu, "From 2008 Wenchuan earthquake to 2013 Lushan earthquake (in Chinese)," Scientia Sinica Terrae, vol. 43, pp. 1064-1072, 2013.

[25] J. Liu, G. Yi, Z. Zhang et al., "Introduction to the Lushan. Sichuan M7.0 earthquake on 20 April 2013," Chinese Journal of Geophys (in Chinese), vol. 56, no. 4, pp. 1404-1407, 2013.

[26] L. Chen, Y. Ran, H. Wang, Y. Li, and X. Ma, "The Lushan M S7.0 earthquake and activity of the southern segment of the Longmenshan fault zone," Chinese Science Bulletin, vol. 58, no. 28-29, pp. 3475-3482, 2013.

[27] W. Liu, P. Dong, J. Liu, and H. Guo, "Evaluation of threedimensional shape signatures for automated assessment of post-earthquake building damage," Earthquake Spectra, vol. 29, no. 3, pp. 897-910, 2013.

[28] Z. Liao, L. Chen, H. Bai, and M. Ding, "Adaptive alpha-Shapes plane point cloud boundary extraction method," Journal of Changsha University of Science \& Technology, vol. 16, no. 2, pp. 15-21, 2019. 